\title{
Slash Fanfiction and Media Representation of the LGBTQ+ Community
}

\author{
Allison Bradley ${ }^{1 *}$
}

\begin{abstract}
There is a serious lack of popular media that focuses on people other than the hegemonic norm of white, straight, able-bodied, men. Queer media in particular is lacking in representation of queer characters, whose narratives often involve inaccurate and misleading stereotypes [1]. However, there are forms of queer media that are happening outside the main sphere of media production. One of these subcultures is 'slash fanfiction,' also referred to as 'slash.' This subculture has grown in popularity since the 1960 s, but it has not been studied in great detail. To understand the extent to which slash has emerged due to the lack of accurate queer portrayals in the media, this study will analyze data from an online survey of slash readers and writers. Research regarding this subculture, often called a phenomenon, would ultimately help to advance LGBTQ+ (lesbian, gay, bisexual, trans, queer and more) people.
\end{abstract}

Keywords

Media - Slash Fanfiction - LGBTQ

${ }^{1}$ Department of Sociology, University of North Texas

*Faculty Mentor: Dr. Michael Thompson

\section{Contents}

Introduction

1 Literature Review

2

1.1 Media Representation of LGBTQ+ Individuals . . 2

1.2 Heteronormativity in Queer Media . . . . . . . . . 2

1.3 Queer Reading Practices . . . . . . . . . . . . . 3

2 Methods

3 Results

3.1 Slash as a Subset of Media Representation . . . . 4

4 Conclusion

Author Biography

References

\section{Introduction}

Media has an enormous impact on people, and thus the quality, accuracy, and quantity of various portrayals of peoples, concepts, and ideas are not something to take lightly. There is a serious lack of popular media that focuses on people other than the hegemonic norm of white, straight, able-bodied, men. But at the same time, there is an over-representation of marginalized peoples in a negative light, contributing and furthering harmful stereotypes of the oppressed.

There is a dearth of queer characters represented in the media, and current queer characters and narratives follow stereotypical paths that leave much to be desired [1]. However, there are other forms of queer media being put forward that are happening outside the main sphere of media production. One of these subcultures is 'slash fiction,' or simply referred to as 'slash.' This subculture has grown in popularity since the 1960s, but it is one that has not been studied in great detail outside of a focus on, perhaps the most popular example of it, Star Trek [2]. Slash fiction is a subsection of fanfiction, or "fiction written by the fans of any popular narrative, be it a novel, a TV series, or a film" [3], that takes a preexisting nonromantic same-gender relationship from a piece of media and reworks it into a fan-written story in which said relationship is now one of a romantic and/or sexual nature. Slash fiction is "named for the '/ or 'slash' between the names of the characters that the stories render queer. Slash, by definition, deals with same-sex characters that in the parent narrative are avowedly or assumedly heterosexual" [2].

I suspected there would be a facet of agency for queer individuals who engage in slash. I thought that there would be more variety in all of these aspects than is believed, first. because there has been too little research on the subject in general to flatly accept stereotyped generalizations and, second, because existing research suggests that there is much more to be learned about the slash population [4].

Research and theory support the perceptions that there are more types of slashers than is presumed and that there is agency, intent, and potential incorporated into slash participation [4]. However, I suspected that there would be negative opinions and perceptions of slash in addition to the positive. It is a fact that slash has a bad reputation and has a large amount of stigma associated with it, so it would not be surprising if the results reflected that. 
Because the group of people who were studied are a lesserknown subculture, giving them voice and understanding the motivations, feelings, and interests of this population were primary goals. With this context in mind, and after careful examination of the relevant literature dealing with slash fiction and LGBTQ+ media representation, I conducted a study using a survey with slash participants and analyzed and evaluated their responses for their relationships with LGBTQ+ media representation.

It is easy to make the leap that people might become involved with slash because they are displeased with current queer media, but this cannot be proved without proper research. Research regarding this subculture, often called a phenomenon, would ultimately be beneficial to the advancement of LGBTQ+ (lesbian, gay, bisexual, trans, queer and more) people; media influences people, and studies involving various forms of queer media production may prove helpful to improving relations for LGBTQ+ people.

It is for this reason that I sought to research slash fiction and its relationship with LGBTQ+ media representation. When approaching this topic, I hoped to tackle three questions: who is reading and/or writing slash fiction, what are some of the motivations/reasons for people who engage with slash, and what are the opinions and perceptions of slash and the slash community? Furthermore, how do the answers to these questions intersect and interact with their relationship to LGBTQ+ media representation?

I suspected that there would in fact be a large number of women who read and write slash fiction, and they will probably make up the majority of those who engage with slash. However, I also suspected that there would be a sizeable portion of queer women among them rather than the presumed stereotype of only straight women reading and writing slash fiction. I also was fairly positive that there would be a much broader range of reasons and motivations for engaging with slash fiction than is commonly believed.

The most common stereotypes associated with slash readers and writers are that their only reason for reading and/or writing slash fiction is for sexual or sexually gratifying purposes. Some slashers do have this as a reason for taking part in slash culture, but I expected that there would be several other factors to explain participation in slash.

\section{Literature Review}

My research focuses on any possible connections between the production/consumption of slash fiction and the influence of the media, queer or otherwise. The topics I have found among the literature are: the influence of media representation on LGBTQ+ individuals, pervasiveness of heteronormativity and heterosexism in queer media representation, and uses of queer reading practices among slash participants.

\subsection{Media Representation of LGBTQ+ Individuals}

After Ellen came out on her 1998 sitcom Ellen, there seemed to be an increase in queer-media representation. The presence of queer characters and queer celebrities was becoming more prominent with the rise of new television programs and musicians. Gomillion and Giuliano [5] postulate that with the rise of LGBTQ+ figures in the media, these figures may well have had an impact on the lives of LGBTQ+ individuals. In their article, they discuss the results of their own data collection from Gay, Lesbian, and Bisexual (GLB) respondents. The overwhelming response was that media had affected multiple aspects of the respondents' GLB identities. The media influenced three areas: their self-realization, their coming-out process, and their current identity as a GLB individual [5].

Representations of GLB characters/stories and GLB media figures influenced many of the respondents' lives, in both positive and negative ways. Their findings suggest that positive representations of GLB individuals can affect selfperception: positive representations can lead individuals to have higher self-efficacy. Conversely, negative representations of GLB identity in media led to feelings of shame and often low self-esteem. But it is not only negative portrayals of GLB individuals that have a negative effect: a lack of GLB representation also negatively impacted the respondents.

Respondents reported feeling isolated and excluded from popular forms of media. This lack of representation often led some respondents to find aspects of themselves in media with no LGBTQ+ characters or individuals. For instance, one respondent saw part of his own identity in X-Men because the characters in that story were also treated as different and excluded from society [5]. It is disheartening an individual only felt they could relate to what society would consider a "monster."

Many respondents also expressed frustration with the way that GLB individuals were represented. It seems that only certain stereotypical depictions of GLB characters are represented, creating a rather narrow range of expression for GLB individuals to work with in everyday life [5]. The findings of this study are relevant to my area of research because I believe that lack of diverse queer representation may lead LGBTQ+ individuals to seek other forms of media to fill in the gaps. If an individual can find no representation of her/himself in media, then perhaps they will read between the lines and create their own interpretations of the media, just as slash fiction does.

\subsection{Heteronormativity in Queer Media}

Some regarded the year 2003 as a breakthrough for queermedia representation. There were a total of eight gay leading characters that season, an increase from the five gay leading characters of the previous season. Avila-Saavedra [1] argues that there is in fact nothing queer about these supposedly queer shows; hence the name of the paper, "Nothing Queer about Queer Television: Televized Construction of Gay Masculinities." In his paper, he evaluates three of the shows that aired during this supposedly "breakthrough" year for elements of hegemonic masculinities and heteronormativity. In his analysis, he finds that gay characters are represented in a way that 
conforms to traditional standards of masculinity and do little to subvert heteronormative narratives. Furthermore, these gay characters are clearly marketed for heterosexual consumption.

Dhaenens [6] echoes this sentiment in his paper, which examines a fan-made web series that edits and recuts a popular soap opera in Germany. The original soap opera had a subplot that focused on a gay couple, but the web series edits the show so that this gay couple is the main focus. Dhaenens discusses how this can be seen as an act of resistance against the heteronormative portrayals of the gay characters in the original body of work. Delegating queer narratives and stories to the sidelines of the show posits queerness as an accessory to the heterosexual leads. Furthermore, the gay characters' identities are defined with regard to the strict binary of homosexual/heterosexual, even though many of the gay characters previously had heterosexual relationships. The original show leaves little room for a variety of queer interpretation.

Padva [7] tackles a different aspect of the way that heteronormativity and heterosexism affect the content and quality of LGBTQ+ media. In particular, Padva focuses on the presence of bullying against LGBTQ+ individuals in media representations. Padva touches on how the almost overrepresentation of bullying seems to be geared more for heterosexual viewers than for LGBTQ+ individuals who may be consuming this media. Even when LGBTQ+ people are present or are the subject of certain media, the media is clearly not made for these individuals.

These articles are relevant to my research because I believe that it is not just a lack of representation in general that may lead individuals to slash, but a lack of quality representation. Quantity means nothing if every character is an offensive stereotype or a side character with a bland storyline.

\subsection{Queer Reading Practices}

Dhaenens and colleagues bring up the concept of queer reading practices in relation to slash fiction. Queer reading is a familiar topic within queer theory, but they argue that there is little consideration of the potential that slash fiction has as an agent of queer reading. In this paper, the authors suggest that slash fiction is not just merely a different interpretation of the source material, but a deliberate act of subversion and retaliation against norms regarding gender, masculinity, and sexuality. The following two papers give examples of how participants in slash engage in these queer reading practices [4].

Slash fiction is not a new concept. The popularity of slash fiction is the legacy of the "original" slash fandom: Star Trek. People have been pairing Kirk and Spock together for over forty years now, and according to Falzone [2], Star Trek was the perfect piece of media to start this trend, perhaps even the only franchise that could have started it. Falzone argues that through queer reading practices, individuals are able to interpret the archetypes within the story as evidence for a queer romantic and/or sexual relationship between Kirk and Spock.
MacDonald's study [3] reveals a similar thought process to that of Falzone [2]: many of the respondents argue that Rowling leaving gaps in the story is an incredible opportunity, whether or not there exists an intentional invitation on Rowling's part, to create fan work, and in particular, slash fanfiction. To create fanwork, respondents are interpreting the text through their unique lenses and queer reading practices. This echoes Falzone's idea that perhaps certain tropes, archetypes, or even genres are more susceptible or more conducive to being slashed.

Galbraith focuses his paper on fujoshi, Japanese women who engage in a similar practice of pairing presumably straight men that slashers in the US and in other countries do. Fujoshi use a type of queer reading to find homoerotic cues as a starting point for an imagined relationship between two characters. The source material for their coupling is not intended to have any romantic interpretations of these characters, just as with the source material for slash fiction. But through their own queer reading practice, whether they would identify it as that or not, they subvert the traditional reading of the source material [8].

All of these papers are relevant to my area of study. I am interested in what reasons someone might participate in slash as well as what might make a piece of media "slashable." These give a good baseline of possible motivations for engaging with slash.

\section{Methods}

I identified five key research methods that were used by the recent studies outlined earlier: ethnography, content analysis, meta-analysis, an open-ended survey, and mixed-method research, including both a survey and in-depth interviews. While all of these methods showed promise as potential methods, the open-ended survey used by MacDonald seemed particularly pertinent to what I wished to study. MacDonald sent a questionnaire to twenty-five authors of slash fanfiction whom she knew nothing about except that they wrote slash and spoke in English. Ten respondents replied in six weeks, and MacDonald looked through the responses to determine a brief snapshot of who seemed to be writing slash as well as their different opinions on what slash had to offer them and in particular what Harry Potter offered as a vehicle for slash. Not only was MacDonald's study [3] directly related to slash readers and writers, but her format offered an opportunity for acquiring both quantitative and qualitative data.

Because I was primarily concerned with teasing out whatever insight I could generate about the motivations and behaviors of slash readers and writers, I valued the capacity of an open-ended survey to potentially reach a wide audience and to afford respondents the chance to elaborate. Due to the niche status of those involved with slash, I anticipated I would be using purposive sampling, and thus any quantitative analyses would be limited to in population comparisons. By incorporating open ended survey questions, I would then be able to enrich my findings by collecting qualitative data alongside 
quantitative data.

There were of course drawbacks in choosing an openended survey over a strictly multiple choice survey, or even over interviews. Analyzing textual data is much more time consuming and nuanced. Similarly, the finalized nature of the survey, as well as the anonymous nature of the response, prevents any follow-up questions, such as those featured in a survey. Despite these disadvantages, the combination of convenience from using a survey as well as the potential for a number of detailed responses was appealing and seemed most applicable my research.

My research goal for this particular project, along with better understanding of the population of slash readers and writers, led me to conclude that a purposive sample would be the best way to approach this. I ultimately decided to perform something of a case study, and because I was not going to be collecting many responses from a representative sample, I opted to maximize the richness of data I would collect from this survey by incorporating open-ended questions.

After deciding on a survey using purposive sampling, I chose to gather data from, if possible, 40 or more slash readers age 18 and older. To do this, I wanted to use an online survey and reach out to a group where I knew readers and writers of slash fiction existed. I therefore contacted a website that I knew hosted fanfiction and other fanwork-Archive of Our Own (AO3) — and inquired whether I would be able to survey their users. After being directed to the proper channels and people in question, the Organization for Transformative Works (OTW), the organization that runs AO3, I was informed of the requirements and was granted permission, subject to approval by the University of North Texas' Institutional Review Board (IRB) for ethical research.

After reaching this stage, I wrote my questionnaire, choosing questions that would give me insight into the motivations, histories, opinions, and realities of slash readers and writers with regard to both slash fiction and current LGBTQ+ media representation. After finalizing my questions, I sent them along with my research plan and awaited IRB approval. Upon approval, I loaded my questions into an online survey, along with a beginning disclaimer informing respondents that their responses would be kept confidential and secure.

I then sent proof of my IRB approval survey link to the OTW, where the survey was broadcast with an invitation for readers and writers of slash, age 18 and older, to take the survey in a timeframe of approximately 2 weeks. After the allotted time-frame, I ended up with an overwhelming response rate: 183 people participated in the survey. Pleasantly surprised, I exported the survey into Excel and then began the process of cleaning up my data. I consolidated my questions into quantitative and qualitative sections and began to evaluate the best way to analyze my findings.

At the beginning of the research process, I anticipated that I would focus my quantitative approach on statistical comparisons between the respondents who self-identified as straight and those who did not. However, when considering my focus,
I realized that the best course of action was to concentrate on a qualitative analysis of my open-ended questions through common emergent themes, as there was plenty to work with in the textual responses. Quantitative analysis would be useful in another project focusing on different aspects of the slash experience.

\section{Results}

After reviewing the textual responses, and questioning which areas were best suited for analysis, I determined one key area for thematic analysis. After first attempting to focus and organize results only by specific survey questions, I found this limiting. Given the nature of my survey, I could not, at times, extrapolate the fullest meaning from a response to one question without referencing answers to other questions for context to support my inferences. Some questions were certainly more relevant and pertinent to the analysis I desired, but I did not want to leave out the relevant data that came from a response to a different question, even if the question itself did not directly seem to prompt that topic.

I drew primarily from two specific survey questions "What is your opinion on the current state of media representation for the LGBTQ+ community?" and "Does slash fiction meet any personal needs of yours?"- -but I also incorporated data from other relevant questions and responses. The following topic emerged as the most relevant for analysis: Media Representation and Slash Readers: Opinions of LGBTQ+ Media Representation and Their Relation to Slash Readers' Participation. Prompted and unprompted, the topic of media representation made itself known in respondents' answers. Respondents all had unique relationships to slash fiction and much of this was related to media representation. The relationship between slash fiction and media representation was best explored by analyzing responses through the lens of slash as a subset of representation.

\subsection{Slash as a Subset of Media Representation}

Among the respondents, there was an implication that slash fiction was being used as an additive and/or substitute for mainstream LGBTQ+ media representation, as well as an implication of slash's potential for representation. Good media representation can help individuals feel validated and reassured of their existence and place in society [5], a sentiment that some respondents expressed about slash fiction. Some directly referred to slash as a facet of representation while others' statements intimated that slash served as a possible "substitute means" of representation.

Individuals expressed direct identification of slash as a means of representation, such as in these responses:

"Yes. i have a craving for representation that isn't
satisfied by official media and so I seek it out or
create it myself." (26-29, female, bisexual)

“I probably wouldn't have began reading/writing 
it in the first place if it was more represented in media." (30-39, female, asexual)

"I think the shoddy state of LGBTQ representation in media is part of the reason I enjoy slash so much, for sure. And I honestly prefer it that way. I do not trust mainstream media to represent how I feel, I would much rather read stuff written by queer perverts on the internet, they can get away with much more in a way that feels so much more real." (22-25, female, bisexual)

These responses, and more, make direct reference to having one's identity reflected and represented. The indication is that slash is providing the sense of "this character is like me. I see a place for my existence."

The responses that did not as clearly posit slash as a means for representing one's identity seemed more to express feelings and effects of what media representation can do. Indication of positive benefits that can arise from media representation were present among responses such as these:

"Slash fiction definitely helped me understand my own sexuality as a teenager. In slash fic, being queer was celebrated, supported, often to an unrealistic level and usually, in the case of [Male/Male] slash, involving a squealing fangirl stuffed in the story solely to assure the M/M main pairing that their love was in fact adorable and desirable." (22-25, genderqueer, bisexual)

"I think that back when I was a teenager, the very existence of slash fictions make me understand that I wasn't alone in my feelings." (50 or older, female, bisexual)

The combination of these manifest and latent indicators gives credence to the likeliness that slash is being used as a means of representation among some respondents. When asked about the potential benefits of slash becoming better known, many respondents expressed indications that slash could function as a form of representation through their explanation of potential benefits that are commonly associated with positive media representation. Respondents indicated that the knowledge of the existence of slash could reassure LGBTQ+ individuals of their normalcy, something positive media representation helps to accomplish [5]. Respondents also expressed a sense that awareness of slash fiction might spread tolerance and acceptance among non-LGBTQ+ individuals. These are not simple goals to accomplish, and the fact that such profound statements were made by the respondents parallels the statements from Dhaenens et al. [4] that slash can act as a form of resistance against heteronormativity.

Not all respondents were as optimistic. Some indicated a feeling that slash could not produce significant benefits to society. Others expressed concern about flaws within slash fiction and the slash community, such as misogyny and fetishization.
Some opposed the notion that slash acted as true representation:
"Slash fiction doesn't help me feel represented, it helps me survive being unrepresented. That's different. But it does help me survive. I just wish we didn't always have to fight against the grain, knowing that media creators will never actually "go there," that they'll tolerate us at best and revile us at worst. I wish I didn't have to turn to slash if I want to see myself. (22-25, non-binary woman, asexual lesbian)

"Re: representation: slash is a way of repairing lack of representation in media, NOT a substitute for it. Slash is also a periscope, allowing us to peer around corners and see parts of ourselves (sexually, genderwise, etc.) that we could not look at directly for whatever reason. That is less about representation and more about exploration. Has slash allowed me to explore issues of desire and identity in myself thru fictional proxies? Yes. But it has not increased direct representation in mainstream media OR in fanfic. Slash is a mask and allows all the power that goes with a mask. Representation is a mirror." (30-39, genderqueer, queer)

Both respondents raise interesting and valid points. The fact of the matter is that slash is not creating new representations for LGBTQ+ people, but simply reworking preexisting media. This reworking is not without positive effects, but the notion remains that slash is a Band-Aid to the wound left by under-representation; it may be doing an effective job and is necessary because there was a problem to begin with.

However, while slash fiction may not be perfect solution, the main point to take away is that it should not be discredited as a potential force for change. It may require more work and fine tuning, but the potential for slash as a gateway to better representation is something that merits further study.

\section{Conclusion}

Previous research indicated that flaws existed with LGBTQ+ media representation, such as issues of frequency or that much of the LGBTQ+ media that does exist is perhaps not as accurate or aimed at connecting with LGBTQ+ peoples' lives as one would expect. Despite a piece of media showcasing LGBTQ+ characters and stories, such productions may still be filled with heteronormative ideals and focus. Furthermore, other research indicated that the effects of media representation were not to be ignored. Especially given the finding that, since queer media does make an impact on LGBTQ+ individuals, these aforementioned queer 'role models' may not be affecting these individuals as beneficially as possible.

This study demonstrates that slash fiction is a viable form of positive representation and implies that slash has potential 
as a tool to help combat the issue of a lack of LGBTQ+ media representation. My study further indicates the importance of further understanding and evaluating the way in which media representation, in a variety of forms, affects LGBTQ+ individuals. My respondents' frustration with LGBTQ+ media representation parallels the findings of previous research. This finding - combined with their descriptions of the general role of slash fiction, despite a few important caveats-helps to affirm the worthiness and possible benefits to LGBTQ+ individuals.

I aim to continue investigating slash fiction, hopefully with a quantitative focus, as I was unable to do so with these data, and I aspire to extrapolate vital findings about slash beyond those discussed in this study. I wish, further, to explore the exact areas of concern that slash participants have with the current state of LGBTQ+ media representation, such as issues of quantity, quality, diversity, and more. I hope, as well, to answer some of my initial research questions that I was not able to cover in this project, such as who is reading slash and what are the motivations for reading slash. This project has granted me insight into the depth of potential that slash has as an area of study, and I intend to explore and expand upon this.

Slash fiction challenges people to examine the way heterosexism and heteronormativity are pervasive and unquestioned in their favorite popular media. Slash fiction also allows its authors and readers to explore aspects of sexuality that are not currently found in mainstream popular representations, particularly for slash fiction's LGBTQ+ consumers. The existence of slash gives the chance for LGBTQ+ people to locate alternative representations of themselves, something that is unlikely to be found in other forms of media. Through simply browsing websites such as AO3, users of any age can find a plethora of works devoted to same-gender relationships, a potential resource for any LGBTQ+ person seeking diverse stories of people like themselves, something unlikely to be found in any other medium.

\section{Author Biography}

Allison Bradley graduated Magna cum laude from University of North Texas with a Bachelor's degree in Sociology, possessing a minor in Women's Studies. She presented "Slash Fanfiction and Media Representation of the LGBTQ+ Community" at the Southwestern Social Science Association conference held in Las Vegas, Nevada earlier this year. She plans to attend graduate school in Fall 2017 for sociology, with a focus on sexuality, gender, and media.

\section{References}

[1] G. Avila-Saavedra. Nothing queer about queer television: Televised construction of gay masculinities. Media, Culture and Society, 31:5-21, 2009.

[2] P.J. Falzone. The final frontier is queer: Aberrancy, archetype and audience generated folklore in ' $\mathrm{k} / \mathrm{s}$ slashfiction.'. Western Folklore, 15:243-261, 2005.
[3] M. MacDonald. Harry Potter and the fan fiction phenom. The Gay and Lesbian Review Worldwide, 13:28-29, 2006.

[4] F. Dhaenens, S. Van Bauwel, and D. Biltereyst. Slashing the fiction of queer theory: Slash fiction, queer reading, and transgressing the boundaries of screen studies, representations, and audiences. Journal of Communication Inquiry, 32:335-347, 2008.

[5] S.C. Gomillion and T.A. Giuliano. The influence of media role models on gay, lesbian, and bisexual identity. Journal of Homosexuality, 58:330-354, 2011.

[6] F. Dhaenens. Queer cuttings on youtube: Re-editing soap operas as a form of fan-produced queer resistance. European Journal of Cultural Studies, 15:442-456, 2012.

[7] G. Padva. Media and popular culture representations of LGBT bullying. Journal of Gay and Lesbian Social Services, 19:105-118, 2006.

[8] P.W. Galbraith. Fujoshi: Fantasy play and transgressive intimacy among "rotten girls" in contemporary japan. Signs, 37:211-232, 2011. 